\title{
Representativeness of Participants in a Lifestyle Intervention Study in Obese Pregnant Women - the Difference between Study Participants and Non-Participants
}

\author{
Joanna Gesche Kristina Renault Kirsten Nørgaard Lisbeth Nilas \\ Department of Obstetrics and Gynecology, Hvidovre Hospital, Hvidovre, Denmark
}

\section{Key Words}

Interventions to increase physical activity - Lifestyle factors · Social determinants · Lifestyle intervention · Pregnancy $\cdot$ Representateviness

\begin{abstract}
Objective: To examine the representativeness of participants attending a lifestyle intervention study addressing obese pregnant women. Methods: Retrospective comparison of baseline data, attendance to oral glucose tolerance test (OGTT) during pregnancy, and pregnancy outcome in eligible women stratified according to study participation. Of 750 eligible women with a self-reported BMI $>30 \mathrm{~kg} / \mathrm{m}^{2}$, and a live singleton pregnancy, 510 were eligible for inclusion and 425 were randomized to either active intervention $(n=284)$ or to standard obstetric care $(n=141)$ including two standard OGTT. The 85 women who declined participation or were excluded due to competing diseases and 240 women who did not respond to the initial invitation received the same standard care. Results: The randomized women had similar BMI but a lower parity and age, and were more frequently non-smokers, born in Denmark and married or cohabitating with their partner than the non-participants. Women participating in the trial had a higher compliance to the second OGTT compared to non-participants, also after correcting for age and nationality. There was no difference in pregnancy outcome, i.e., fetal weight and length, gestational age as well as mode of delivery. Conclusion: Women declining participation in a randomized lifestyle intervention study in pregnancy have characteristics indicating they are those who might benefit the most from lifestyle intervention.
\end{abstract}


Gesche et al.: Representativeness of Participants in a Lifestyle Intervention Study in Obese Pregnant Women - the Difference between Study Participants and Non-Participants

\section{Introduction}

The global obesity epidemic is a complex problem. It is related to food abundance and a sedentary lifestyle but is also influenced by various sociodemographic and economic factors. The long-term consequences of overweight and obesity are increased risks of type 2 diabetes and cardiovascular diseases and a reduced life expectancy. Maternal obesity is associated with adverse pregnancy outcomes [1-3] and increases the risk of non-communicable disease in the offspring $[4,5]$.

Reducing pre-pregnancy weight should be the ideal strategy for limiting the risk of adverse pregnancy outcome in obese pregnant women and possibly improving the health of the outcome. General lifestyle interventions addressing parts of populations have poor success, and individually tailored personal interventions are costly and time consuming [6]. Women planning pregnancy are expected to be highly motivated for lifestyle changes, but no large-scale studies have proven effective. This strategy is challenged by half of the pregnancies being unplanned and by the fact that women planning pregnancies do not generally seek pre-pregnancy counseling [7]. The risks associated with obesity may also be underestimated by obese pregnant women who due to the obesity epidemic might consider themselves normal and healthy [8].

Some intervention studies $[9,10]$ find that lifestyle intervention in obese pregnant women reduces maternal weight gain during pregnancy and reduces the risk of gestational diabetes, but does not seem to affect neonatal outcome. Reviews of the existing literature $[6,11-14]$ have described heterogeneity of the intervention studies concerning study size, population characteristics, outcome measures, and types of intervention. While systematic reviews carefully address the quality of the studies, the impact of possible selection bias is rarely discussed.

We have performed a large randomized lifestyle intervention study in 425 obese pregnant women and wanted to investigate whether women accepting participation are representative for all eligible obese pregnant women in the study period [15].

\section{Material and Methods}

A lifestyle intervention study in obese pregnant women was performed in 2009-2012 at Hvidovre Hospital in Copenhagen, Denmark, serving about 7,000 births annually. Women with a self-reported BMI > $30 \mathrm{~kg} / \mathrm{m}^{2}$ constituted about $4 \%$ of the population and were, as part of our routine antenatal program, invited to a consultation with a dietician and additionally sent written information about the interventional study. If they were eligible and accepted study participation, they were afterwards randomized 1:1:1 into a group receiving follow-up on physical activity monitored by a pedometer, a group receiving follow-up on both physical activity and diet, and a control group receiving standard care [15].

All included women were advised to aim for a gestational weight gain of less than $5 \mathrm{~kg}$, and participants in the two intervention groups monitoring physical activity were recommended a daily step count of 11,000.

Women with a live singleton pregnancy and a normal nuchal scan were eligible. Exclusion criteria for study participation were severe illness competing with lifestyle intervention or the lack of ability to read and speak Danish.

All pregnant women in Denmark are offered frequent consultations with health care professionals, including their general practitioner and a midwife, as well as ultrasound examinations. During the study period, the standard regimen for obese women was a single consultation with a dietician, a standardized 2-hour oral glucose tolerance test (OGTT) in gestational week 17-20 and 27-30, and an obstetric consultation including fetal weight estimation by ultrasound at 36 weeks of gestation.

All women with BMI $>30 \mathrm{~kg} / \mathrm{m}^{2}$ during the inclusion period were identified in the registry for the nuchal scan and cross-referenced with a local quality database registering all deliveries at the department. For all women baseline data, such as BMI, parity, age, tobacco smoking, nationality (place of birth), marital and occupational status, as well as data on pregnancy outcome were extracted. We used the educational level of the 
Gesche et al.: Representativeness of Participants in a Lifestyle Intervention Study in Obese Pregnant Women - the Difference between Study Participants and

Non-Participants

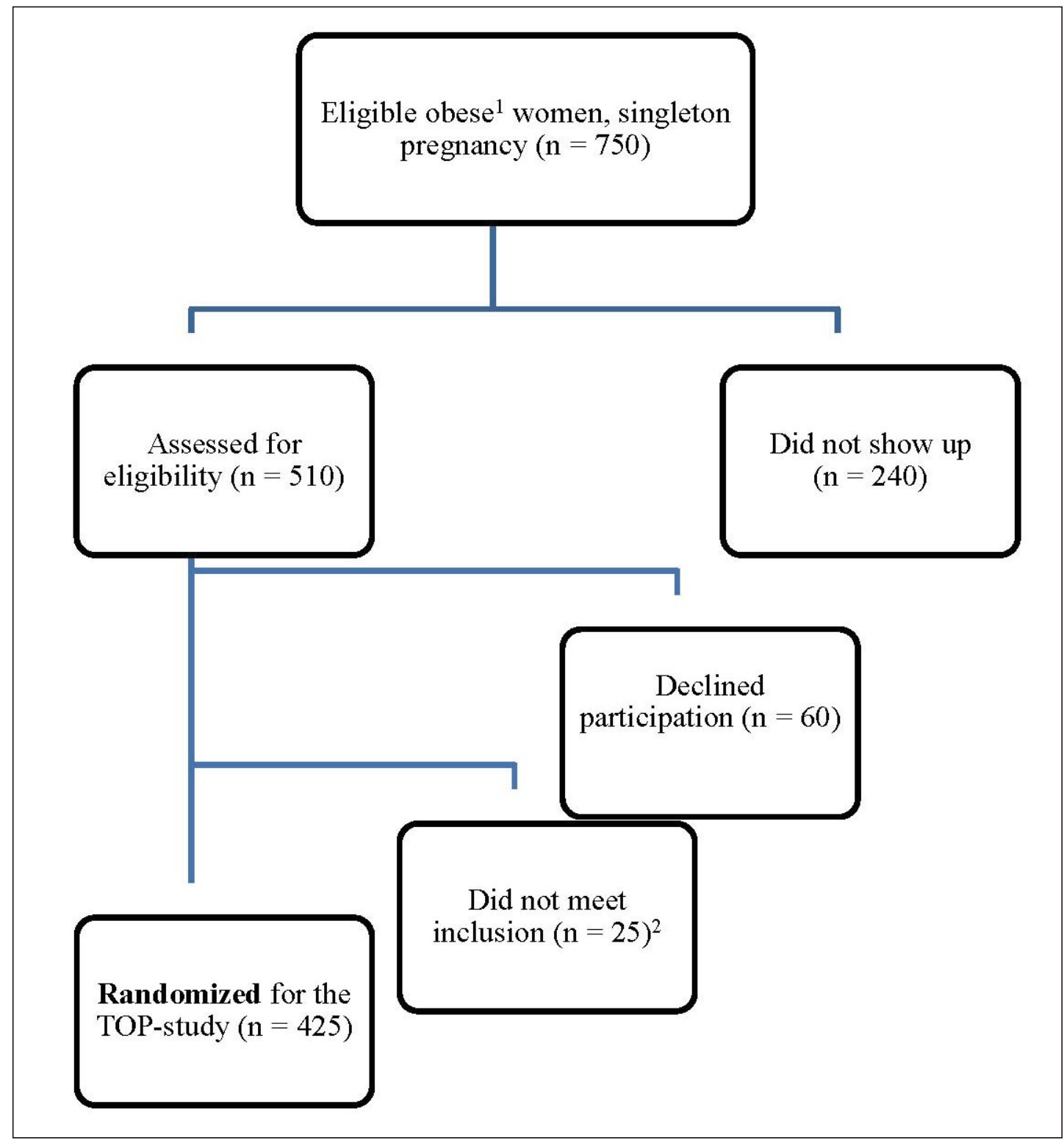

Fig. 1. Flow-chart of the study population. ${ }^{1}$ Obese: $B M I>30 \mathrm{~kg} / \mathrm{m}^{2} \cdot{ }^{2} 16$ due to linguistic problems, 9 due to competing diseases; 9 were added to the non-participants.

women as a parameter for social status. Each listed occupation was checked at the official homepage of 'The Ministry of Children and Education' in order to determine which education leads to the occupation at hand. If more than one educational level was possible, the highest was chosen. We expressed educational level in years after primary school, and stratified the women into four groups: no education, finished secondary school or practical occupational training, university studies at bachelor or master level and PhD students.

We compared pregnancy outcome, including fetal weight and length, gestational age, mode of delivery, the use of epidural analgesia, placental weight and umbilical artery $\mathrm{pH}$, in non-randomized women with that of the women randomized to standard regimen treatment. A neonate was considered small for gestational age (SGA) when weighing under 2,500 g and large for gestational age (LGA) when weighing over 4,000 g [16, 17]. The $Z$ score is the birth weight expressed in percentage deviation from the expected mean in the sex and gestational age-matched population [18]. 
Gesche et al.: Representativeness of Participants in a Lifestyle Intervention Study in Obese Pregnant Women - the Difference between Study Participants and Non-Participants

Table 1. Baseline data in participants and non - participants in a lifestyle intervention trial in obese pregnant women $^{\mathrm{a}}$

\begin{tabular}{llll}
\hline & $\begin{array}{l}\text { Participants } \\
(\mathrm{n}=425)\end{array}$ & $\begin{array}{l}\text { Non-participants } \\
(\mathrm{n}=249)\end{array}$ & Significance \\
\hline BMI, mean (SD), kg/m ${ }^{2}$ & $34.1(4.0)$ & $33.9(3.8)$ & 0.66 \\
Median, range & $32.8(29.0-52.2)$ & $32.9(27.1-46.5)$ & \\
30.0-34.9, \% & 67.1 & 67.0 & \\
$35.0-39.9, \%$ & 22.1 & 18.1 & \\
$>40, \%$ & 9.9 & 10.9 & $<0.05^{*}$ \\
\hline Age, mean (SD), years & $31.1(4.5)$ & $29.9(4.9)$ & \\
Median (range) & $31.1(18-44)$ & $30.0(18-41)$ & \\
$\quad<25$ years, \% & 8.7 & 15.3 & $<0.05^{\star}$ \\
25-30 years, \% & 32.2 & 31.7 & \\
$\quad>30$ years, \% & 59.1 & 53.0 & $<0.001^{\star}$ \\
\hline Parity, mean (SD) & $0.55(0.72)$ & $0.83(0.89)$ & \\
Median (range) & $0(1-4)$ & $1(0-5)$ & $<0.001^{\star}$ \\
$\quad$ Nulliparous, \% & 55.7 & 42.5 & $<0.05^{\star}$ \\
$\quad$ Uniparous, \% & 35.1 & 37.0 & $<0.001^{\star}$ \\
$\quad$ Multiparous, \% & 9.2 & 20.5 & \\
\hline Danish nationality, \% & 91.8 & 68.5 & 0.40 \\
\hline Married/cohabitating, \% & 90.1 & 86.6 & \\
\hline Smokers, \% & 8.1 & 19.5 & \\
\hline Social status - women, \% & & & \\
$\quad$ No education & 7.2 & 39.4 & \\
$\quad$ Secondary school / occupational training & 46.4 & 9.0 & \\
University studies & 39.5 & & \\
PhD student & 6.9 & 41.6 & \\
\hline
\end{tabular}

*Wilcocxon's rank sum test; ${ }^{*}$ chi-squared test.

The interventional study was registered at the Danish National Committee on Biomedical Research Ethics (ID-number: H-D-2008-119) and at http://clinicaltrials.gov (ID-number: NCT01345149). The current study was approved by the Danish Data protection Agency (Jr.n.2012-41-0400).

Data on baseline values and outcomes for all pregnancies at the department are available in a local quality database, and relevant data can be extracted for scientific purposes. For ethical reasons data on women actively declining participation cannot be used, and it is therefore not possible to compare women attending the randomization visit and non-participants. We therefore chose to compare the randomized women who gave informed consent to those not attending the inclusion visit.

All data were entered in a separate database and compared using the statistical software package ' $\mathrm{R}$ ', version 2.15.0. Comparisons between groups were performed with either Wilcoxon's rank sum test or by the chi-squared test, using a 5\% level as significant. In order to determine how participating in the randomized controlled trial (RCT) affects pregnancy outcome, we performed multiple linear and logistic regression analysis with pregnancy outcome variables (fetal weight and length, gestational age, arterial umbilical cord $\mathrm{pH}$, mode of delivery and epidural analgesia) and attendance to the OGTT as outcome, and study participation, age and nationality as explanatory variables. Numerical variables - assumed to be normally distributed - were kept as such and categorical data was given 1 for 'Yes' and 0 for 'No'. The results were expressed as coefficients with $\mathrm{p}$ value or OR with $95 \%$ confidence interval (95\% CI) both unadjusted and adjusted for age and nationality separately. 
Gesche et al.: Representativeness of Participants in a Lifestyle Intervention Study in Obese Pregnant Women - the Difference between Study Participants and Non-Participants

Table 2. Attendance to scheduled oral glucose tolerance test (OGTT) at gestational weeks and the 2-hour plasma glucose concentrations in obese pregnant women participating and not participating in a lifestyle intervention trial. Values are given as mean (SD) or percentages

\begin{tabular}{llll}
\hline & $\begin{array}{l}\text { Participants } \\
(\mathrm{n}=425)\end{array}$ & $\begin{array}{l}\text { Non-participants } \\
(\mathrm{n}=249)\end{array}$ & Significance \\
\hline OGTT at week 14-20, \% & 89.6 & 84.7 & 0.08 \\
OGTT at week 27-30, \% & 81.6 & 43.0 & $<0.001^{* * *}$ \\
2-hour glucose, mmol/l & $7.0(1.3)$ & $7.0(1.2)$ & 1.0 \\
$\quad 310$ mmol/l week 14-20, \% & 3.1 & 3.3 & 1.0 \\
2-hour glucose, mmol/l & $6.8(1.3)$ & $6.9(1.4)$ & \\
$\quad 210$ mmol/l week 27-30, \% & 2.0 & 1.9 & \\
\hline *** Chi-squared test. & & & \\
\hline
\end{tabular}

\section{Results}

Of 750 women meeting the inclusion criteria of a maternal BMI $>30 \mathrm{~kg} / \mathrm{m}^{2}$ and a live singleton pregnancy without malformations at the nuchal translucency scan, 510 attended the initial dietary advisory consultation and 240 did not show up (fig. 1). Of the 510 women screened, 25 did not fulfill the criteria for study inclusion - 16 due to linguistic problems and 9 due to competing diseases. 60 women declined study participation and 425 were randomized (284 to active intervention and 141 to standard obstetric care serving as a control group). Baseline data were only available in 9 of the women who did not fulfill the inclusion criteria, and these were added to the 240 non-participants resulting in 249 obese non-randomized women.

Comparison of the participants in the RCT and women not participating showed identical BMI and identical distribution of the women in the different BMI classes (table 1).

Women accepting randomization were younger, had a lower parity, and were more frequently non-smokers, born in Denmark and married or cohabitating with their partner than non-participants. The educational level of the women was identical in the two groups.

The non-participants were significantly less likely to attend the second OGTT than were the randomized women (table 2).

Of the 249 non-randomized women and the 141 women randomized to the control group, 231 and 134 women, respectively, gave birth at the hospital and data on the delivery were available. Pregnancy outcome, fetal weight, gestational age, and the risk of LGA and SGA did not differ in the two groups, and there were no major differences in the mode of delivery (table 3).

Logistic regression analyses showed a significant relationship between study participation and showing-up for the second OGTT. Participants in the RCT have significantly greater odds of showing up for the second OGTT, both unadjusted and adjusted for age and for ethnicity (table 4).

The linear regression analysis shows no effect of study participation on fetal weight, fetal length, gestational age, arterial umbilical cord $\mathrm{pH}$, and epidural analgesia, neither in the unadjusted analyses nor when adjusting for age and ethnicity. Study participants have greater odds of vaginal delivery, both unadjusted and corrected for age and ethnicity. There is also a significant relationship between study participation and acute cesarean section, which disappears when corrected for ethnicity (table 4). 
Table 3. Pregnancy outcome in participants and non-participants in a lifestyle intervention trial in obese pregnant women

\begin{tabular}{llll}
\hline Outcome & $\begin{array}{l}\text { Participants } \\
(\mathrm{n}=134)\end{array}$ & $\begin{array}{l}\text { Non-participants } \\
(\mathrm{n}=231)\end{array}$ & Significance \\
\hline Gestational age (SD), days & $278(12)$ & $276(15)$ & 0.19 \\
\hline Fetal weight, g & $3,608(549)$ & $3,518(587)$ & 0.13 \\
$\quad$ Mean (SD) & $3,641(1,223-5,280)$ & $3,540(480-5,040)$ & 0.54 \\
$\quad$ Median (range) & 3.0 & 3.9 & \\
$\quad<2,500, \%$ & 24.6 & 17.7 & \\
$\quad>4,000, \%$ & $2.4(13.3)$ & $0(-64$ to 49$)$ & \\
Z-score mean & $1.0(-40$ to 37) & 2.6 & 0.29 \\
Z-score median & 1.5 & $51.7(3.0)$ & 0.45 \\
Z-score $\leq 22$ (\%) & $52.0(2.6)$ & $679(155)$ & 0.22 \\
\hline Fetal length (SD), cm & $671(163)$ & $7.25(0.09)$ & 0.41 \\
\hline Placental weight (SD), g & $7.23(0.08)$ & 67.5 & \\
\hline Arterial umbilical cord pH (SD) & 62.7 & 87.2 & 0.06 \\
\hline Vaginal delivery, \% & 85.7 & 12.8 & \\
$\quad$ Non-instrumental & 14.3 & 32.5 & 0.86 \\
$\quad$ Instrumental & 37.3 & 45.3 & 54.7 \\
Cesarean section, \% & 64.0 & 40.5 & \\
$\quad$ Acute & 36.0 & 42.2 & \\
$\quad$ Elective & & &
\end{tabular}

\section{Discussion}

A RCT with sufficient power is the best way to investigate the effect of an intervention by ensuring that social and individual differences are equally distributed between the groups. The RCT has some limitations, especially when addressing lifestyle intervention. Individuals accepting randomization may not be representative for the women fulfilling the inclusion criteria, and participation in a RCT may also change the behavior of participants randomized to the control arm. In the current study we examined the representativeness of the participants in a randomized lifestyle intervention trial in obese pregnant women.

We found that women accepting participation in a RCT differed in baseline characteristics, but had the same BMI as those not participating. The non-participants had a higher parity. A possible explanation could be that nulliparous women are more willing to change their behavior in order to optimize the health conditions of their first offspring, and the multiparous women already have children and lack time or energy to try to change lifestyle and participate in time-consuming studies. The non-participating women were also slightly younger, more often single, and more often smoking. Smoking is a high-risk factor for adverse pregnancy outcome, and this group of young women may be the ones who would benefit the most from a lifestyle intervention. The difference in social risk factors is limited in our study, which could be explained by the socially rather homogenous Danish population in comparison to other nations, the free access to the health care system and the fact that the study addressed pregnant women who had already established contact with the hospital and thus are a more unselected part of the population than in studies relying on willingness to attend a trial only. 


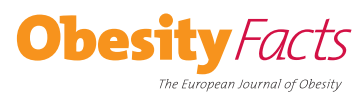

\begin{tabular}{l|l}
\hline Obes Facts 2014;7:351-360 \\
\hline DOI: 10.1159/000369769 & $\begin{array}{l}\text { @ } 2014 \text { S. Karger GmbH, Freiburg } \\
\text { www.karger.com/ofa }\end{array}$ \\
\hline $\begin{array}{l}\text { Gesche et al.: Representativeness of Participants in a Lifestyle Intervention Study in } \\
\text { Obese Pregnant Women - the Difference between Study Participants and } \\
\text { Non-Participants }\end{array}$
\end{tabular}

Table 4. The effect of participating in a randomized controlled study on attendance to OGTT and pregnancy outcome with and without adjusting for age and nationality

\begin{tabular}{|c|c|c|c|}
\hline Outcome & Unadjusted & Adjusted for age & Adjusted for nationality \\
\hline Show up to OGTT at week $14-20, \%$ & $\begin{array}{l}1.56(0.98-2.48) \\
p=0.06\end{array}$ & $\begin{array}{l}1.59(0.99-2.53) \\
p=0.052\end{array}$ & $\begin{array}{l}1.37(0.81-2.33) \\
p=0.24\end{array}$ \\
\hline Show up to OGTT at week $27-30, \%$ & $\begin{array}{l}5.90(4.17-8.42) \\
p=\leq 0.001\end{array}$ & $\begin{array}{l}6.05(4.26-8.67) \\
p=\leq 0.001\end{array}$ & $\begin{array}{l}5.80(3.88-8.84) \\
p=\leq 0.001\end{array}$ \\
\hline Blood glucose OGTT 1 & $\begin{array}{l}0.02(-0.29 \text { to } 0.24) \\
p=0.85\end{array}$ & $\begin{array}{l}0.02(-0.20 \text { to } 0.24) \\
p=0.89\end{array}$ & $\begin{array}{l}(-0.24 \text { to } 0.26) \\
p=0.92\end{array}$ \\
\hline Blood glucose OGTT2 & $\begin{array}{l}-0.01(-0,29 \text { to } 0.27) \\
p=0.94\end{array}$ & $\begin{array}{l}(-0.30 \text { to } 0.26) \\
p=0.91\end{array}$ & $\begin{array}{l}-0.12(-0.43 \text { to } 0.18) \\
p=0.42\end{array}$ \\
\hline Diagnosed with GDM & $\begin{array}{l}1.44(0.90-2.28) \\
p=0.13\end{array}$ & $\begin{array}{l}1.44(0.90-2.29) \\
p=0.13\end{array}$ & $\begin{array}{l}1.12(0.47-2.51) \\
p=0.80\end{array}$ \\
\hline Gestational age, days & $\begin{array}{l}1.90(-1.04 \text { to } 4.84) \\
p=0.20\end{array}$ & $\begin{array}{l}1.57(-1.38 \text { to } 4.52) \\
p=0.30\end{array}$ & $\begin{array}{l}1.46(-2.20 \text { to } 5.13) \\
p=0.44\end{array}$ \\
\hline Fetal weight, $g$ & $\begin{array}{l}90.43(-31.98 \text { to } 212.84) \\
p=0.15\end{array}$ & $\begin{array}{l}69.80(-52.44 \text { to } 192.03) \\
p=0.26\end{array}$ & $\begin{array}{l}109.78(-43.78 \text { to } 263.35) \\
p=0.16\end{array}$ \\
\hline Fetal length, $\mathrm{cm}$ & $\begin{array}{l}0.28(-0.33 \text { to } 0.89) \\
p=0.37\end{array}$ & $\begin{array}{l}0.17(-0.44 \text { to } 0.78) \\
p=0.58\end{array}$ & $\begin{array}{l}0.36(-0.41 \text { to } 1.13) \\
p=0.36\end{array}$ \\
\hline Placental weight, $\mathrm{g}$ & $\begin{array}{l}87.65(-22.66 \text { to } 197.95) \\
p=0.12\end{array}$ & $\begin{array}{l}94.08(-17.06 \text { to } 205.22) \\
p=0.10\end{array}$ & $\begin{array}{l}96.10(-42.31 \text { to } 234.51) \\
p=0.17\end{array}$ \\
\hline Arterial umbilical cord $\mathrm{pH}$ & $\begin{array}{l}-0.01(-0.03 \text { to } 0.01) \\
p=0.22\end{array}$ & $\begin{array}{l}-0.01(-0.03 \text { to } 0.01) \\
p=0.25\end{array}$ & $\begin{array}{l}-0.002(-0.03 \text { to } 0.02) \\
p=0.86\end{array}$ \\
\hline Vaginal delivery, \% & $\begin{array}{l}16.8(9.68-30.30) \\
p \leq 0.001\end{array}$ & $\begin{array}{l}17.40(9.93-31.77) \\
p \leq 0.001\end{array}$ & $\begin{array}{l}11.66(5.96-24.45) \\
p \leq 0.001\end{array}$ \\
\hline Cesarean section, $\%$ & $\begin{array}{l}1.21(0.78-1.89) \\
p=0.39\end{array}$ & $\begin{array}{l}1.15(0.73-1.80) \\
p=0.54\end{array}$ & $\begin{array}{l}1.44(0.82-2.58) \\
p=0.21\end{array}$ \\
\hline Acute & $\begin{array}{l}1.76(1.03-3.00) \\
p=0.039\end{array}$ & $\begin{array}{l}1.73(1.01-2.97) \\
p=0.047\end{array}$ & $\begin{array}{l}1.57(0.81-3.13) \\
p=0.50\end{array}$ \\
\hline Elective & $\begin{array}{l}0.72(0.39-1.29) \\
p=0.28\end{array}$ & $\begin{array}{l}0.67(0.36-1.21) \\
p=0.20\end{array}$ & $\begin{array}{l}1.08(0.49-2.41) \\
p=0.86\end{array}$ \\
\hline Epidural (\%) & $\begin{array}{l}1.15(0.74-1.80) \\
p=0.53\end{array}$ & $\begin{array}{l}1.23(0.78-1.94) \\
p=0.37\end{array}$ & $\begin{array}{l}1.17(0.67-2.07) \\
p=0.58\end{array}$ \\
\hline
\end{tabular}

Women who do not have Danish as their native language may be lacking sufficient language skills to understand spoken and written information in Danish, were more frequently not participating in the randomized arms. This is partly expected since they were excluded from the randomization to begin with. In Denmark, immigrants and their descendants constitute $10.4 \%$ of the population [19], and especially immigrants from the Middle East, both in Denmark and in other countries, have an increased risk of obesity and obesity-related complications [20]. The use of the health care system by immigrants differs from country to country possibly depending on the access and cost of health care but also on the ethnicity of the immigrants [21,22]. The Danish public health care is free of charge and is used to the same extent or more frequently by immigrants than non-immigrants [23]. The lower participation rate of ethnic women may therefore reflect a cultural attitude towards obesity, which may not be 
considered a risk factor. In some ethnic societies physical activity is not promoted or may be considered as a health hazard for adults and for pregnant women. The main reason for the lower degree of participation of ethnic women could simply be their inability to read and understand Danish, which is a general challenge for the health care system that needs to be addressed [24].

The much larger number of women meeting for the second OGTT illustrates the effect of participation in a RCT. An OGTT is unpleasant for pregnant women, but having attended once, the randomized women were much more willing to attend the second one compared to merely half of the non-participants. The regression analyses show that this difference can be explained neither by the age difference nor by the difference in nationality between study participants and non-participants. Generally, women accepting randomization to lifestyle interventions are more willing to change their behavior and hope to be randomized to active treatment [25], and generally study participants are more motivated and have a better compliance to study interventions than non-participants [26]. Women randomized to standard care may therefore be prone to changes of their behavior and adopt a healthier lifestyle by changing the diet and increasing their physical activity, leading to an underestimation of the effect of the intervention. Participation in a study is associated with a closer surveillance with increased possibility of diagnosing and treating complications. In our study the pregnancy outcome and the 2-hour glucose levels were essentially identical in the women randomized to the control group and non-participating women. It is possible that the general focus on promoting a healthy lifestyle was adopted by the non-participating women, but may also indicate that the differences in baseline characteristics have little or no effect on glucose tolerance during pregnancy and pregnancy outcome.

The data used in this study were extracted from a local quality database and are entered by senior staff members only according to the department's guidelines, thus a systematic bias is not likely to have occurred. Socioeconomic status is often measured as a combination of occupation, income and occupational status, but is a complex issue which also is affected by the partner's education and income as well as the wealth of the family. Educational level is a major determinant of health in women, and is also a significant risk factor for obesity [27]. We estimated social group from the patients' current profession, which relies on self-reported data collected during pregnancy and did not include present occupation. The educational level may be overestimated, but this should apply evenly to all groups.

Ideally a randomized interventional trial should be able to express efficacy not only by a per-protocol and intention-to-treat-analysis but also to describe the possible selection bias in those accepting participation. For ethical reasons we were not able to compare eligible women accepting and declining randomized intervention, but could only compare parameters between randomized women and women who did not show up and did not actively decline study participation. A person's right to decline study participation must be accepted, but is has to be remembered that the results of a RCT cannot be generalized to women with other characteristics than those of the included. We also, unfortunately, lacked baseline data on 16 women who were excluded from randomization. This is methodologically incorrect, but as they only constitute about $1 \%$ of the study population, the possible error seems limited. We furthermore only had delivery data on those who gave birth at the hospital. Some had moved away from the catchment area of the hospital during pregnancy, and some were in labor referred to other hospitals in the area due to lack of capacity at the department. These events are expected to be evenly distributed in the different groups of women.

Despite the differences in baseline characteristics between the randomized and nonrandomized women, we found no difference in pregnancy duration, fetal weight, the risk of LGA or SGA fetuses, or the results of the OGTT during pregnancy. Also in the regression analyses, we found no relationship between study participation and pregnancy outcome. 
Gesche et al.: Representativeness of Participants in a Lifestyle Intervention Study in Obese Pregnant Women - the Difference between Study Participants and Non-Participants

There was a trend towards higher fetal weight in the randomized women. The lack of significance might be explained by a lack of power, but differences in baseline characteristics variables may also affect fetal growth. Adjusting for age and nationality had no significant effect on the pregnancy outcome. We did not correct for other differences in baseline data with a possible effect on pregnancy outcome, e.g. smoking, which was more common in non-participants and is associated with increased risk of SGA [28], or parity, which is associated with increased risk of macrosomia [29]. However, our results indicate, that the differences between randomized and non-randomized women have little effect on pregnancy outcome. It is therefore not likely, that the effect of the lifestyle intervention in the RCT is severely affected by selection bias [15].

We found a difference in the odds of delivering vaginally between participants and nonparticipants. Denmark has a liberal policy on performing cesarean sections on maternal request. Since women participating in the RCT have a greater frequency in attending prenatal visits, they have developed a better relationship with their caregivers and hence listen to them when deciding about the birth giving process, which could be explanatory for the difference found.

In summary, we find that obese pregnant women accepting lifestyle intervention constitute a selected group of women who are older, more often nulliparous, and have a healthier lifestyle and a higher compliance to pregnancy consultations compared to nonparticipants, but the differences are limited.

Several factors are important for achieving a larger participation rate, such as a better understanding of the risk factors involved in being obese and pregnant, teaching the benefits of lower weight gain without sounding condescending, scheduling appointments on the same day to avoid transportation time and costs, offering interventions that interfere least with everyday life, and increased focus on those with a significant social burden or language deficiencies. However, a higher participation rate first of all requires proof that lifestyle intervention benefits the mother, the pregnancy outcome as well as the child's health, both in the short and in the long term.

\section{Disclosure Statement}

The authors have nothing to disclose.

\section{References}

1 Bhattacharya S, Campbell D, Liston W, Bhattacharya S: Effect of body mass index on pregnancy outcomes in nulliparous women delivering singleton babies. BMC Public Health 2007;7:168.

-2 Ovesen P, Rasmussen S, Kesmodel U: Effect of prepregnancy maternal overweight and obesity on pregnancy outcome. Obstet Gynecol 2011;118:305-312.

-3 Guelinckx I, Devlieger R, Beckers K, Vansant G: Maternal obesity: pregnancy complications, gestational weight gain and nutrition. Obes Rev 2008;9:140-150.

4 Catalano PM, Ehrenberg HM: The short- and long-term implications of maternal obesity on the mother and her offspring. BJOG 2006;113:1126-1133.

5 Hochner H, Friedlander Y, Calderon-Margalit R, Meiner V, Sagy Y, Avgil-Tsadok M, et al: Associations of maternal prepregnancy body mass index and gestational weight gain with adult offspring cardiometabolic risk factors: the Jerusalem Perinatal Family Follow-up Study. Circulation 2012;125:1381-1389.

-6 Tanentsapf I, Heitmann BL, Adegboye AR: Systematic review of clinical trials on dietary interventions to prevent excessive weight gain during pregnancy among normal weight, overweight and obese women. BMC Pregnancy Childbirth 2011;11:81.

7 Williams L, Zapata LB, D’Angelo D V, Harrison L, Morrow B: Associations between preconception counseling and maternal behaviors before and during pregnancy. Matern Child Health J 2012;16:1854-1861. 
Gesche et al.: Representativeness of Participants in a Lifestyle Intervention Study in Obese Pregnant Women - the Difference between Study Participants and Non-Participants

8 Yaemsiri S, Slining MM, Agarwal SK: Perceived weight status, overweight diagnosis, and weight control among US adults: the NHANES 2003-2008 Study. Int J Obes (Lond) 2011;35:1063-1070.

-9 Nascimento SL, Surita FG, Parpinelli M., Siani S, Pinto e Silva JL: The effect of an antenatal physical exercise programme on maternal/perinatal outcomes and quality of life in overweight and obese pregnant women: a randomised clinical trial. BJOG 2011;118:1455-1463.

-10 Vinter CAMD, Jensen DMP, Ovesen PD, Beck-Nielsen HD, Jørgensen JSP: The LiP (Lifestyle in Pregnancy) Study: a randomized controlled trial of lifestyle intervention in 360 obese pregnant women. Diabetes Care 2011;34: 2502-2507.

11 Oteng-Ntim E, Varma R, Croker H, Poston L, Doyle P: Lifestyle interventions for overweight and obese pregnant women to improve pregnancy outcome: systematic review and meta-analysis. BMC Med 2012;10:47.

$\$ 12$ Dodd JM, Grivell RM, Crowther CA, Robinson JS: Antenatal interventions for overweight or obese pregnant women: a systematic review of randomised trials. BJOG 2010;117:1316-1326.

13 Thangaratinam S, Rogozinska E, Jolly K, Glinkowski S, Roseboom T, Tomlinson JW, et al: Effects of interventions in pregnancy on maternal weight and obstetric outcomes: meta-analysis of randomised evidence. BMJ 2012;344:e2088.

-14 Streuling I, Beyerlein A, von Kries R: Can gestational weight gain be modified by increasing physical activity and diet counseling ? A meta-analysis of interventional trials. Am J Clin Nutr 2010;92:678-687.

15 Renault KM, Nørgaard K, Nilas L, Carlsen EM, Cortes D, Pryds O, et al: The Treatment of Obese Pregnant Women (TOP) study: a randomized controlled trial of the effect of physical activity intervention assessed by pedometer with or without dietary intervention in obese pregnant women. Am J Obstet Gynecol 2013;210: 134.e1-9.

16 Lawrence EJ: Part 1: a matter of size: evaluating the growth-restricted neonate. Adv Neonatal Care 2006;6: 313-322.

17 Lawrence EJ: A matter of size: part 2: evaluating the large-for-gestational-age neonate. Adv Neonatal Care 2007;7:187-197.

18 Marsál K, Persson P, Larsen T, Lilja H, Selbing A, Sultan B: Intrauterine growth curves based on ultrasonically estimated foetal weights. Acta Paediatr 1996;85:843-848.

19 Danmarks statistik: Indvandrere i Danmark 2012. Copenhagen, Danmarks statistik, 2012.

20 Millett C, Khunti K, Gray J, Saxena S, Netuveli G, Majeed A: Obesity and intermediate clinical outcomes in diabetes: evidence of a differential relationship across ethnic groups. Diabet Med 2008;25:685-691.

21 Heslehurst N, Rankin J, Wilkinson JR, Summerbell CD: A nationally representative study of maternal obesity in England, UK: trends in incidence and demographic inequalities in 619323 births, 1989-2007. Int J Obes 2010;34:420-428.

-22 Vinikoor-Imler LC, Messer LC, Evenson KR, Laraia BA: Neighborhood conditions are associated with maternal health behaviors and pregnancy outcomes. Soc Sci Med 2011;73:1302-1311.

23 Nielsen SS, Hempler NF, Waldorff FB, Kreiner S, Krasnik A: Is there equity in use of healthcare services among immigrants, their descendents, and ethnic Danes? Scand J Public Health 2012;40:260-270.

$24 \mathrm{Ng} \mathrm{C}$, Newbold KB: Health care providers' perspectives on the provision of prenatal care to immigrants. Cult Health Sex 2011;13:561-574.

25 Hertogh EM, Schuit AJ, Peeters PHM, Monninkhof EM: Noncompliance in lifestyle intervention studies: the instrumental variable method provides insight into the bias. J Clin Epidemiol 2010;63:900-906.

-26 Bornhöft G, Maxion-Bergemann S, Wolf U, Kienle G, Michalsen A, Vollmar H, et al: Checklist for the qualitative evaluation of clinical studies with particular focus on external validity and model validity. BMC Med Res Methodol 2006;6:56.

27 Marmot M, Allen J, Bell R, Bloomer E, Goldblatt P: WHO European review of social determinants of health and the health divide. Lancet 2012;380:1011-1029.

-28 Mutsaerts MA, Groen H, Buiter-Van der Meer A, Sijtsma A, Sauer PJ, Land JA, Mol BW, Corpeleijn E HA: Effects of paternal and maternal lifestyle factors on pregnancy complications and perinatal outcome. A populationbased birth-cohort study: the GECKO Drenthe cohort. Hum Reprod 2014;29:824-834.

29 Li G, Kong L, Li Z, Zhang L, Fan L, Zou L, Chen Y, Ruan Y, Wang X, Zhang W: Prevalence of macrosomia and its risk factors in china: a multicentre survey based on birth data involving 101,723 singleton term infants. Paediatr Perinat Epidemiol 2014;28:345-350. 